\title{
Early laser damage research at State Optical Institute in Leningrad
}

Leonid Glebov, Vladimir Komolov

Leonid Glebov, Vladimir L. Komolov, "Early laser damage research at State Optical Institute in Leningrad," Proc. SPIE 10805, Laser-Induced Damage in Optical Materials 2018: 50th Anniversary Conference, 1080506 (16 November 2018); doi: $10.1117 / 12.2502569$

SPIE. Event: SPIE Laser Damage, 2018, Boulder, Colorado, United States 


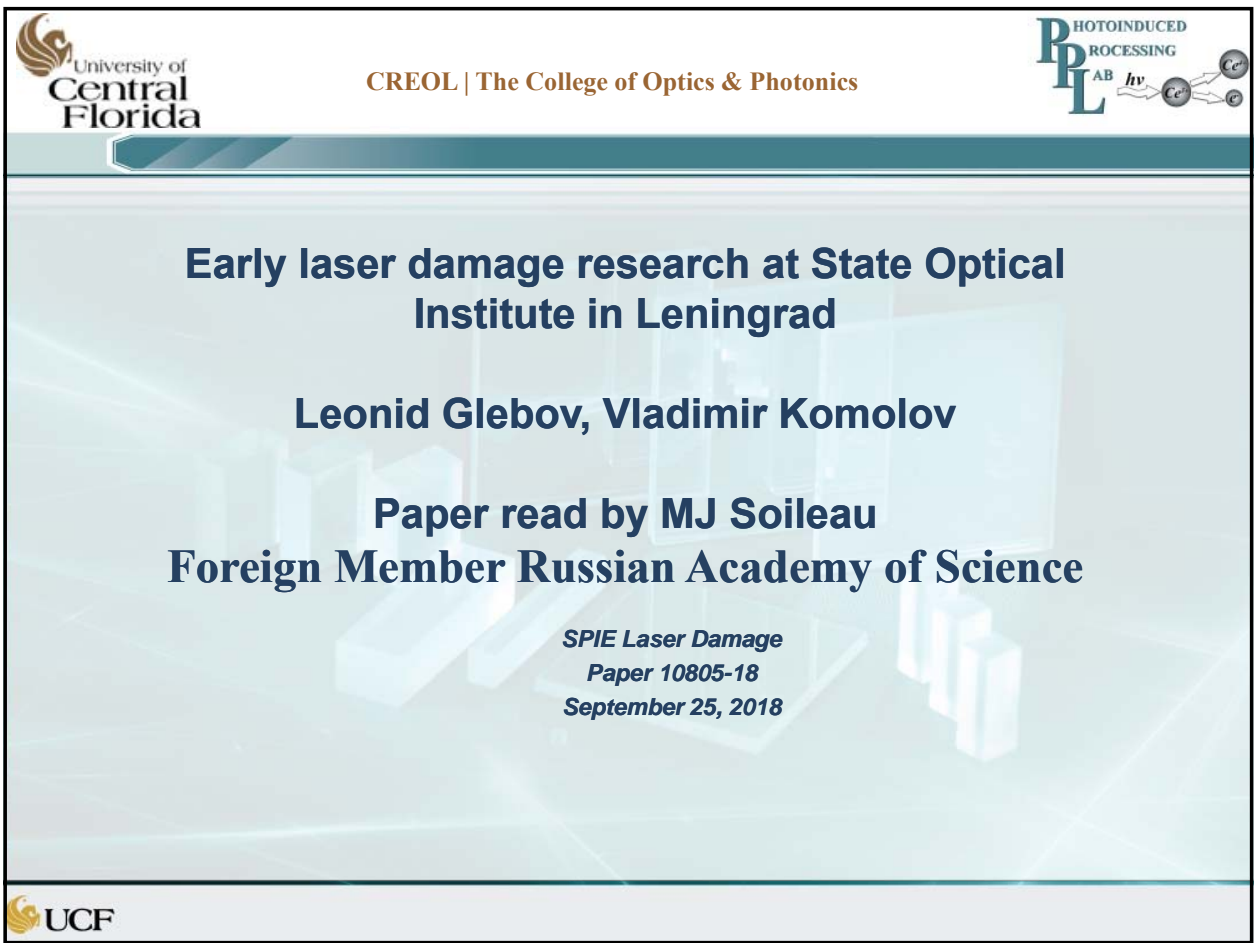

\begin{tabular}{l} 
1. State Optical Institute \\
2. Basic researches in laser induced damage \\
3. Technology for high power laser optics \\
4. Testing facility for interaction of laser radiation with materials \\
\hline UCF \\
\hline
\end{tabular}




\begin{tabular}{|c|c|}
\hline State Optical Institute \\
Государственный Оптический Институт им. С.И. Вавилова (ГОИ) \\
Literal translation: Vavilov State Optical Institute (SOI) \\
\hline main research, development and prototyping national facility in optics, USSR \\
\hline The main administrative building, Leningrad
\end{tabular}

\section{State Optical Institute



Russian Soviet Republic established on November $7^{\text {th }}, 1917$

Civil war in Russia - from 1918 to 1922.

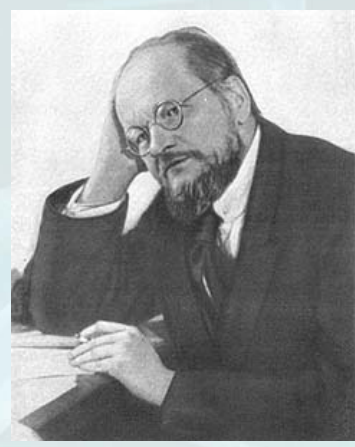

Dmitry Rozhdestvenskiy: Director in 1918-1932.

The first meeting of Research Council of Optical Institute was conducted on December $15^{\text {th }}, 1918$ and approved by the Commission of Education for funding. Employment - 24 people in 1918, 250 people in 1932. 


\section{State Optical Institute}

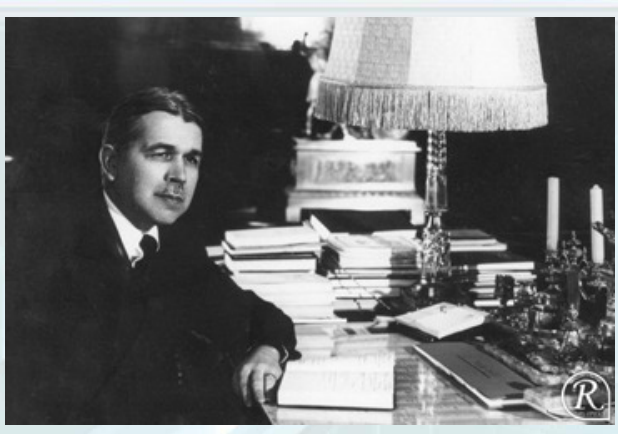

Sergey Vavilov: Associate Director - Research Supervisor from 1932-1945.

Most known discovery - explanation of the nature of glow produced by high speed particles in dielectric media that was observed by his PhD student Cherenkov. At the time of Nobel prize award, he already passed away and his name did not appear in award authorship.

UCF

State Optical Institute

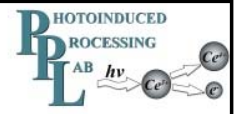

C $>>120$

Sergey Vavilov: Associate Director - Research Supervisor from 1932-1945.

Fast growth of the institute -600 people in 1936. The institute included following departments - spectroscopy, computing optics, illuminating optics, photography, applied physical optics, physiological optics, color laboratory, and chemical section.

Vavilov was a PhD adviser for future leaders in rare earth ions spectroscopy and lasers (Peter Feofilov, left) and nonlinear optics and laser damage (Alexey BonchBruevich, right).

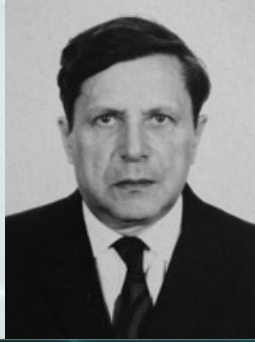




\begin{tabular}{|c|c|c|}
\hline \multicolumn{3}{|c|}{ State Optical Institute } \\
\hline \multirow{2}{*}{\multicolumn{3}{|c|}{$\begin{array}{l}\text { Further development of the institute to Optical Empire - } 12500 \text { employees in } \\
1985 . . . \text { the world's largest optics organization! } \\
\text { The institute included three manufacturing plants and two subsidiaries - optical } \\
\text { materials and complex testing. Directions of activity - from basic researches in } \\
\text { all areas of optics, to applied researches, to development of technology of } \\
\text { optical materials, optical components and optical systems, to manufacturing of } \\
\text { prototypes and supplying them to different customers from agriculture to } \\
\text { military to space exploration. }\end{array}$}} \\
\hline & & \\
\hline & $\begin{array}{l}\text { Mikhail Miroshnikov (left) - director } \\
\text { from } 1966 \text { to } 1989 . \\
\text { Eugeniy Tsarevskiy (right) - } \\
\text { Research Supervisor from } 1956 \text { to } \\
1981 .\end{array}$ & \\
\hline UCF & & \\
\hline
\end{tabular}

State Optical Institute
Research, development and fabrication of optical materials.
In 1923, D. Rozhdestvenskiy initiated establishing of the Leningrad Optical
Glass Plant that scientifically was supervised by Optical Glass laboratory at the
Optical Institute where glass compositions and technology were developed. In
1969, the plant and the optical glass department were combined into a
subsidiary of SOI where basic research, development and production of optical
glasses, crystals, ceramics and fibers were conducted.
Guriy Petrovskiy (left) was
appointed as a Director
The main administrative
building (right)




\section{State Optical Institute}

Research and complex testing of optical systems

In 1969, M. Miroshnikov initiated establishing of a new subsidiary of SOI in small town of Sosnoviy Bor (Pine Forest) where large scale optical and laser systems were assembled and tested (total laboratory and manufacturing space about $110,000 \mathrm{~m}^{2}$. High level fabrication facility enabled creation of prototypes that could be delivered to end users.

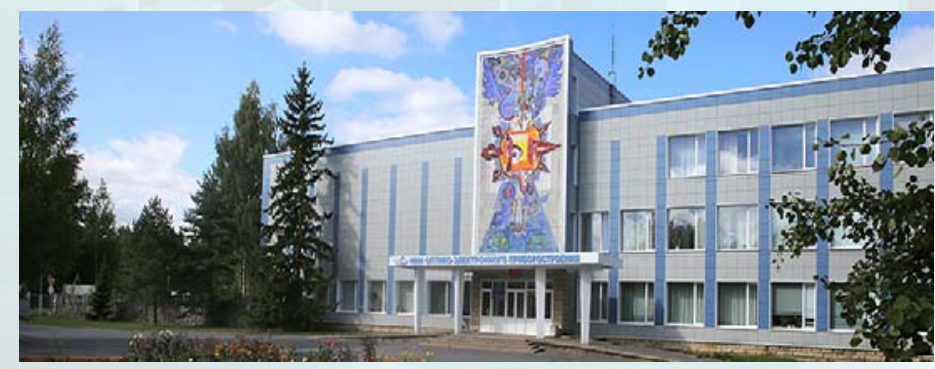

The main administrative building, Sosnoviy Bor

UCF

\section{Laser damage research}
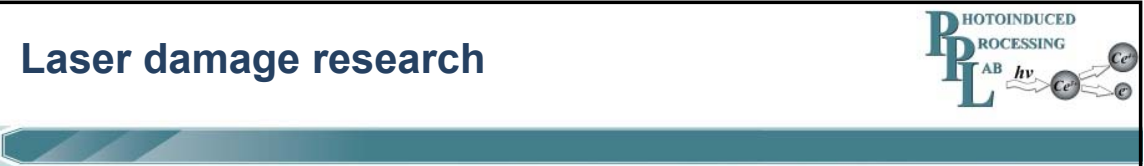

The first laser in the USSR - ruby laser, was set going on June $2^{\text {nd }}, 1961$ by Leonid Khazov and Inna Belousova.

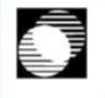

\section{Ииститут лазерной физики ФГУП «ННК "ГОИ им С.И.Вавилова ,}

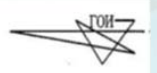

Первый в СССР лазер - рубиновый - запущен в

ГОИ им. С.И.Вавилова

2 июня 1961 года

ст.н. сотр. Л.Д. Хазовым в отделе А.А. Лебедева с участием И.М.Белоусовой



Л.Д. Хазов

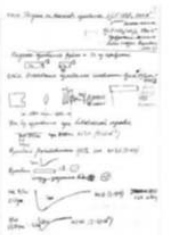

Из рабочего днекника Л.Д. Хазова.

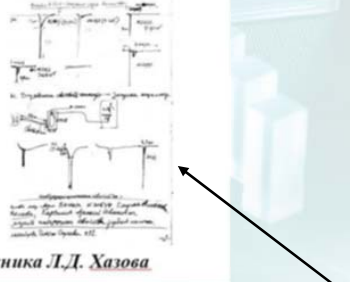

Pages from the lab book 


\section{Laser damage research}

Starting point of heavily funded research in interaction of laser radiation with matter. First demonstration of explosion initiated by laser. Legend. No official confirmation. Parallel in this Country!

From left to right - Lev Koporskiy, Alexey Bonch-

Bruevich, Yakov Imas.

Photo was taken in 1996.

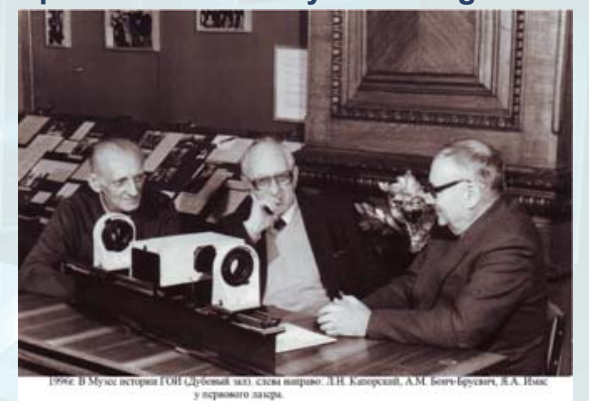

1963. A military delegation visits the first "portable" Nd glass laser with about 1 $\mathrm{J}$ pulse energy. A power supply is hidden in a truck next to the lab window. An arbitrary piece of paper is placed before the laser and laser triggered.

Impressive explosion triggered real funding of the research. The piece of paper was double layered with gun powder between layers.

UCF

\section{Laser damage research}

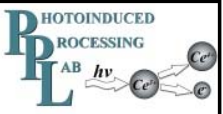

A. Bonch-Bruevich became a scientific leader in a study of laser radiation impact on metals, semiconductors and dielectrics.

From left to right - Alexey

Bonch-Bruevich, Yakov

Imas, Igor Aleshin, Boris

Reichman.

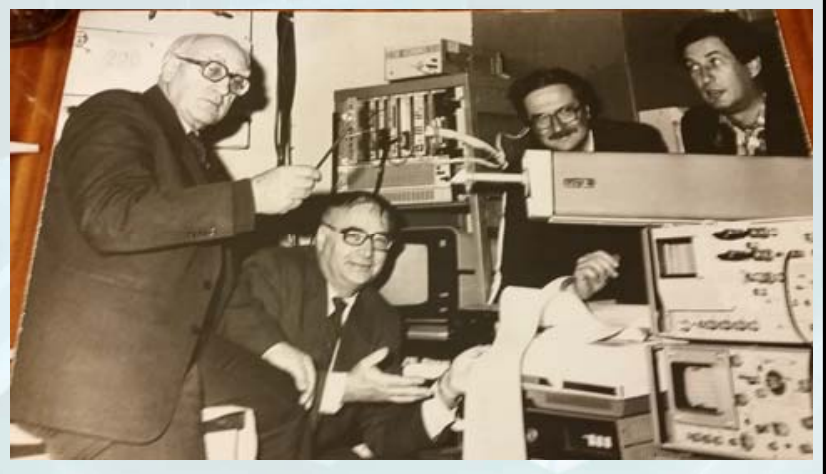

Several experimental groups were established to conduct researches with pulsed and CW lasers working in near and mid IR spectral regions. 


\section{Laser damage research}

Theoretical description was directed to laser plasma in metals and dielectrics, mechanisms of pulsed laser damage of dielectrics, and photoinduced phenomena in semiconductors.
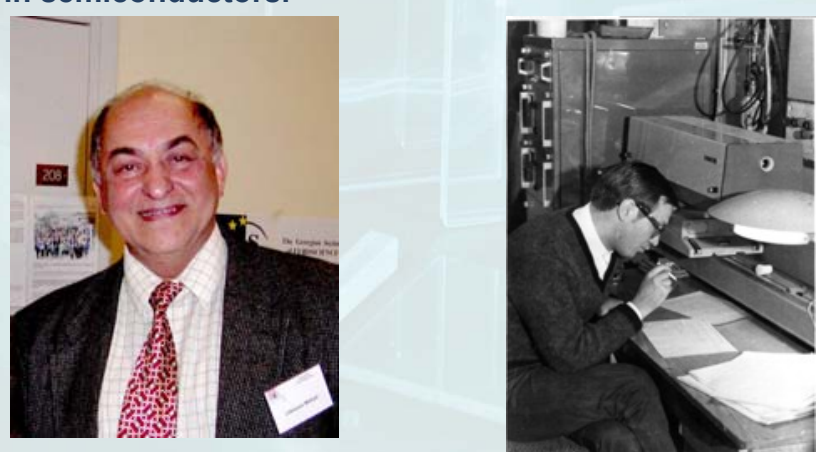

Theoretical study of laser induced processes was conducted by Michail Libenson (left) and Vladimir Komolov (right).

UCF

The first laser damage conference

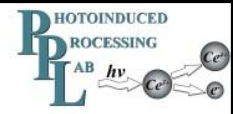

The first laser damage conference gathered researchers mainly from Moscow and Leningrad demonstrating initial progress in this new field of research. Some examples of presentations from SOl are in the following slides.

\section{TESTCA IORHAMOB}

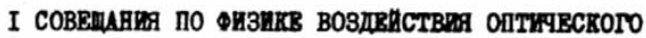

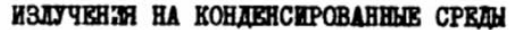

\section{8-3I охтября I969 rom}

г. Ленивград

Abstracts

$1^{\text {st }}$ meeting on physics of optical radiation impact on condensed matter

October 28-31, 1969

Leningrad 


\section{The first laser damage conference}

The most important direction in the beginning was evaporation of metals because of promising military applications. Experimental works were not allowed for public presentations. Therefore, the only theoretical results were presented.

A.M. Bonch-Bruevich, Y.A. Imas, M.N. Libenson, V.E. Okunev, G.S. Romanov, N.S. Skoblya. Heating, melting and nonstationary evaporation of metals under impact of laser radiation. Solutions on nonstationary problem of metal heating by optical radiation and spatial temperature distribution in metal and plasma were demonstrated.

Y.A. Imas, M.N. Libenson. On damage threshold of opaque materials in a media with counter pressure. The problem of evaporation from the surface of heated metal in conditions when partial vapor pressure is smaller than the atmospheric one is solved.

UCF

\section{The first laser damage conference}

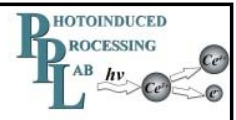

C

The main features of laser damage of transparent dielectrics were described at the early stages of the experimental research.

L.A. Nesterov, A.A. Poplavskiy, I.A. Fersman, L.D. Khazov. Dependence of damage threshold on laser pulse duration. It was shown for glass surface damage energy threshold for nanosecond to microsecond regimes is proportional to square root of pulse duration. It is supposed that dependence is determined by thermal diffusion from the exposed area.

I.A. Fersman, L.D. Khazov. Damage of transparent dielectrics surfaces by laser beam. Shock waves at entrance and exit surfaces of optical glass are studied. It is shown the shock waves propagate to the direction toward the laser beam - to the atmosphere from the front surface and to the bulk of material from the back surface. Pressure in the bulk of optical glass exceeds $10^{4} \mathrm{~atm}$. 


\section{The first laser damage conference}

The main features of laser damage of transparent dielectrics were described at the early stages of the experimental research.

A.M. Bonch-Bruevich, Y.A. Imas, I.V. Aleshin, A.V. Pavshukov. Change of glass surface temperature under impact of laser radiation. Temperature of glass surface layers under impact of microsecond laser pulses is studied. It was found that a thin surface layer of about $30 \mu \mathrm{m}$ shows extremely high absorption that determines kinetics of laser damage.

A.M. Bonch-Bruevich, Y.A. Imas, M.N. Libenson, M.N. Nikitin. Dependence of surface damage threshold of glass under laser radiation on spot size. It was shown that laser damage threshold decreases while laser spot size increases.

Thus, those most important features at dependence of laser damage threshold on pulse duration and spot size were a basis for theoretical explanation of the laser damage phenomenon.

\section{Effect of expending opaque inclusion}

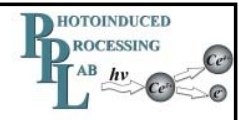

The problem to be solved is how micron size absorbing inclusion could provide damage in macroscale. Modeling has shown that unrealistic high temperatures should be achieved in such an inclusion to provide damage.

The most comprehensive model that describes laser induced damage of transparent materials with absorbing inclusions based on multiple experimental works was developed by $\mathbf{M}$. Libenson, V. Komolov and later with participation of a young theoretician Vitaly Gruzdev. The idea is that at some temperature transparent material becomes opaque. Therefore, the transparent layer adjacent to the heated inclusion becomes opaque increasing the size of the inclusion. At some moment growing opaque shell achieves critical size that generates stresses exceeding damage threshold. This model was experimentally confirmed by direct absorption measurements produced by A. Onokhov.

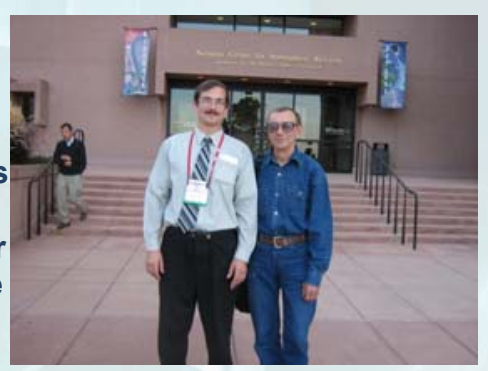




\section{Optical materials for high power applications}

While the main cause of low laser damage threshold for pulsed radiation was the presence of micron sized absorbing inclusions and for CW radiation - bulk absorption, technologies for optical materials with no inclusions and low bulk absorption were developed at the optical material subsidiary.

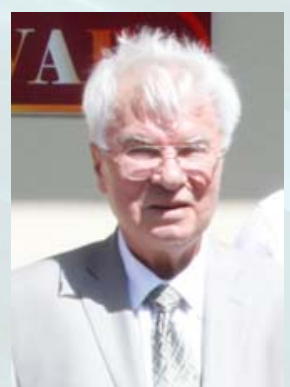

Two directions were explored at the time. The first one is vitreous silicon oxide produced by precipitation from a gas phase resulted from burning $\mathrm{SiCl}_{4}$ in oxygen. This material was produced with diameters up to $500 \mathrm{~mm}$ and it became the main material for passive optical elements in high power laser systems. No inclusions, absorption at the level of few $\mathrm{dB} / \mathrm{km}$ and low nonlinear refractive index made it suitable for both $\mathrm{CW}$ and short pulse lasers. Yuriy Kondratiev supervised this research and development.

\section{Optical materials for high power applications}

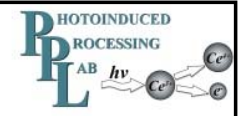

The second direction was a development of multicomponent glasses that could be used as gain media. The first $\mathrm{Nd}$ doped laser glasses were developed by research and G. Karapetyan with his colleagues E. Galant and S. Lunter. Spectroscopic study was conducted by M. Tolstoi.

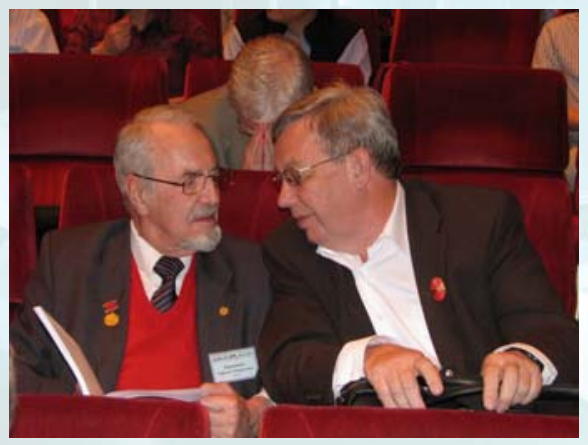

Garegin Karapetyan (left) and Valentin Gapontsev (right) at the Laser Optics Conference. 


\section{Optical materials for high power applications

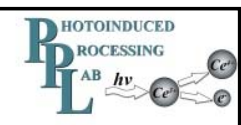

Successful demonstration of glass laser applications for range finders and laser fusion resulted in establishing laser glass laboratory managed by M. Tolstoi (a former PhD student of P. Feofilov) . Extra to development of laser glasses, he committed to develop a technology of high purity multicomponent glass with no inclusion and to study mechanisms of glass stability under impact of UV radiation of pump sources and under exposure to pulsed laser radiation to his $\mathrm{PhD}$ student Leonid Glebov and a researcher Lia Popova.

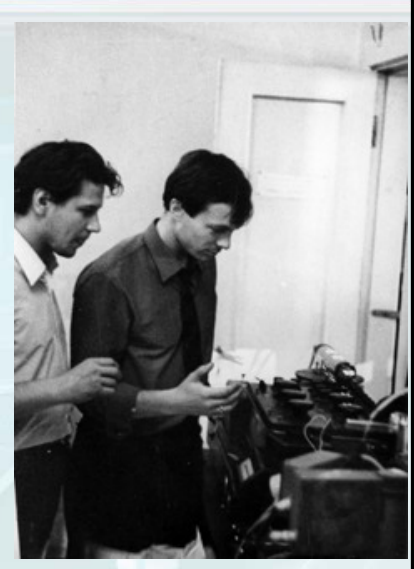

M. Tolstoi (left) and L. Glebov (right) with a cryogenic Nd glass laser

UCF

\section{Optical materials for high power applications

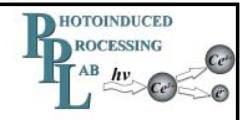

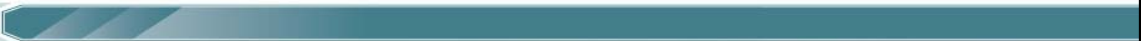

A technology of multicomponent $\mathrm{Na}_{2} \mathrm{O}$ $\mathrm{CaO}-\mathrm{SiO}_{2}$ glass in silica crucible with melting in isolated oxygen atmosphere was developed. 1.5 liter boules of homogeneous glass with no inclusions, concentration of metal impurities below 1 ppm, and absorption of $30 \mathrm{~dB} / \mathrm{km}$ were produced. These glasses were used for multiple researches that enabled determination of electron mobility threshold and radiation induced defect in silicate glasses.

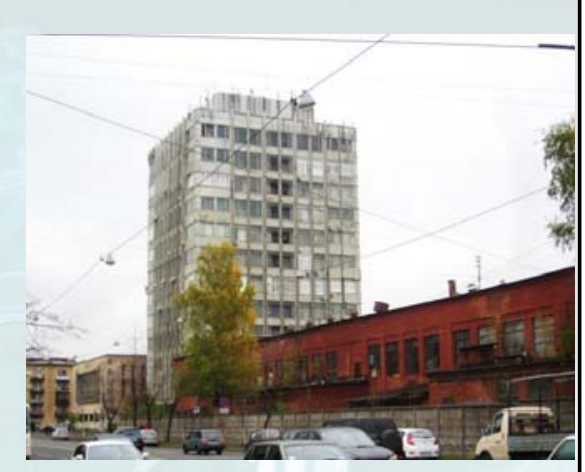

The XIX century constructed building where the first high purity multicomponent glasses were fabricated. 

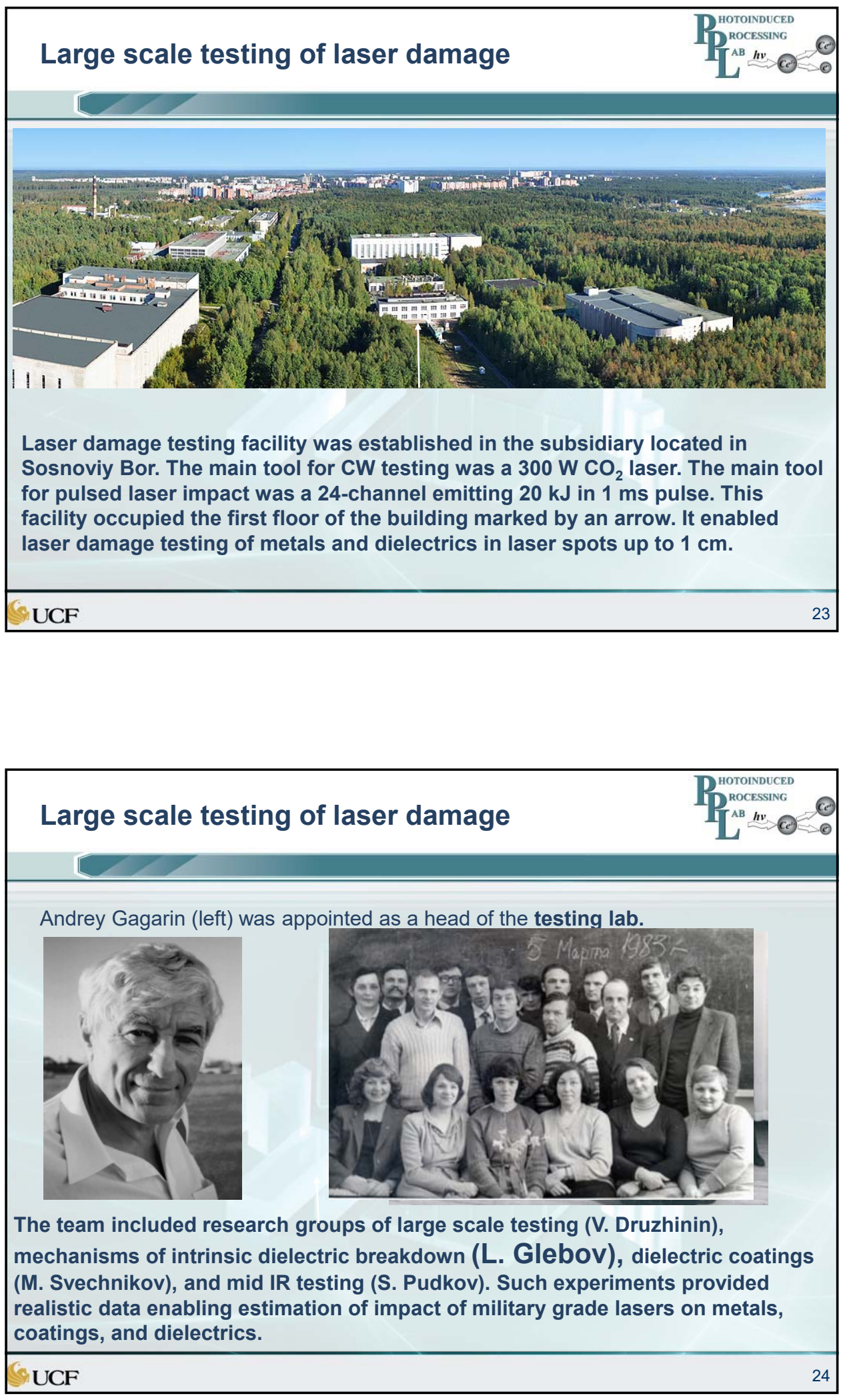


\section{Intrinsic laser induced breakdown}

Glebov (left) group studied intrinsic processes of photoionization and laser damage
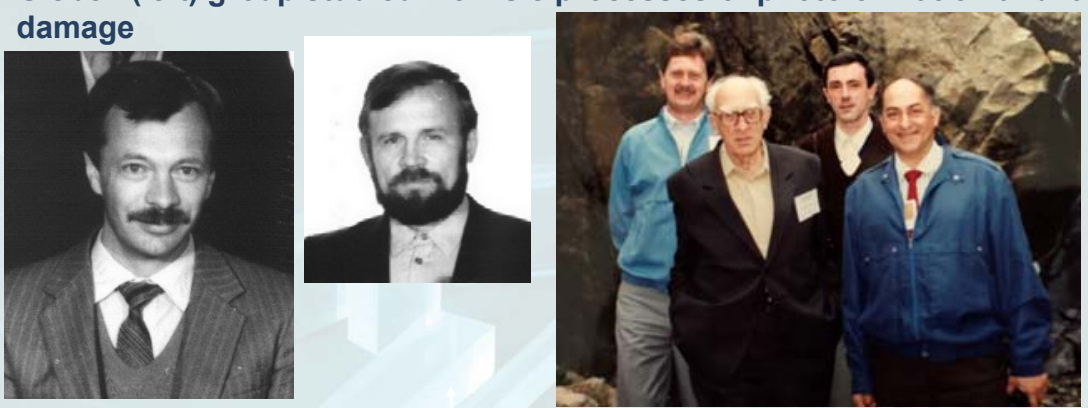

Vladimir Dokuchaev (center) developed a method of extremely low absorption measurements and identified all radiation defects in silicate glass. Those data enabled study of intrinsic laser breakdown. Oleg Efimov (left on the right photo) created a single frequency laser and a focusing system enabled focusing radiation in spots down to $1 / 3$ wavelength. Those measurements provided parameters of intrinsic laser damage.

UCF

\section{Some personal memories}

\section{P $_{\text {HOTOINDUCED }}^{\text {ROCESSING }}$

\section{C}

D Photo in the last slide was taken at Boulder Falls in Boulder Canyon in 1993

$>$ We went on the shout hike to the falls during the meeting lunch break

> It started to snow so we hurried back to the car, only to find that we had locked the keys inside!

> Pre-cellphone days so I crossed the road and stuck out my thumb to hitch a ride back to Boulder

$>$ The first car down the canyon road stopped to pick me up and the driver took me to the police station where I called AAA

$>$ A guy from AAA picked me up, drove me back to the car (where my guest were huddled together in the snow), and broke into the car and we returned to NIST for our meeting...though we were a bit late for the afternoon meeting!

$>$ The Russian visitors returned to Orlando with me in time for Halloween! We had quite a party with the visitors dressed as cowboys and pirates!

> I met Leon, Vitaly, Mike Liebenson, Oleg Efimov (now at HRL), and Academician Bonch-Brevich when I visited Leningrad in 1991 and visited Sosnobiy Bor as well... until then a Secret City.

$>$ 1had been joint research with the GPI in Moscow and traveled to the USSR every year between 1988 and 1991 but Leningrad and GOI were off limits.

> This was the first SPIE meeting in Russia, and on Oct 1 the city name was changed from Leningrad to St. Petersburg....and there was one heck of a party that evening...but stories of that will have to wait for another time. 


\section{The Leningrad team was part of the defense industry. Of course $\mathbf{P}^{\text {HOTOINDCED }}$ there was a team in Moscow that was part of the Soviet Academy
of Science}

$>$ These great scientist were part of the Soviet Academy of Science

$>$ Most famous were Basov and Prokhorov who shared the Nobel Prize for the invention of the laser

$>$ Participating in our meeting were Konov, Garnov, Klimentov, Manenkov, Scherbakov, Dianov, and others in Prokhorov's Institute, the General Physics Institute, who contributed our meeting

$>$ A great team was also at Moscow State University, including Akhmanov, pioneer in self-focusing, V Zadkov, N. Koroteev, Rector of the university, and others

$>$ V. Gapontsev of the Institute of Radio Electronics, and founder of IPG in the USA

$>$ And many others throughout the USSR.

$>$ Thank you for your attention and lets wish good health to our friends and colleagues, Leon and Vitaly!

$>$ And also keep my friend and colleague Boris Zel'dovich in your thoughts. 